\title{
A epistemologia do ensino da arte frente aos parâmetros curriculares nacionais: confluências e oposições conceituais
}

\author{
Art education epistemology and the \\ national guidelines: confluences and \\ conceptual oppositions
}

\author{
Carolina Betioli Ribeiro FISCH*
}

\begin{abstract}
Resumo: O presente trabalho apresenta um panorama das correntes teóricas do Ensino da Arte e propõe uma reflexão sobre as confluências e oposições entre as mesmas, com o objetivo de oferecer subsídios para análise da posição epistemológica dos Parâmetros Curriculares Nacionais de Arte. Concluiu-se que o documento, apesar de oferecer uma proposta muito abrangente e buscar resgatar os conhecimentos específicos da área, apresenta ao longo do texto de fundamentação trechos nos quais se entrecruzam noções com bases teóricas diferenciadas ou mesmo incompatíveis. Assim, ficam comprometidas a coerência e a finalidade de oferecer ao professor de arte fundamentos teóricos sólidos para embasarem sua prática pedagógica.
\end{abstract}

Palavras-chave: arte-educação. epistemologia. parâmetros curriculares nacionais - Arte.

\begin{abstract}
This article presents the scenario of Art Education theoretical guidelines and proposes a reflection about the confluences and oppositions among the guidelines. This is done in order to offer subsidies to the analyses of the epistemological position of the National Guidelines. Despite the fact that the article offers a comprehensive approach and an attempt to recover specific knowledge of the area it presents throughout the theoretical material sections in which notions with differentiated or even incompatible theories are linked. Thus, coherence and the aim of offering a solid theoretical basis so that art teachers can inform their practice is affected.
\end{abstract}

Keywords: art education. epistemology. National Guidelines.

\footnotetext{
* Licenciada em Educação Artística e Bacharel em Artes Plásticas. Email: carolbetioli@gmail.com
}

Olhar de professor, Ponta Grossa, 9(1):159-182, 2006. 


\section{INTRODUÇÃO}

O Ensino da Arte ${ }^{1}$, no Brasil, encontra-se em situação vergonhosa. A prática em sala de aula mostra que o professor que ensina Arte - que denominamos hoje Arte-Educador - não possui conviç̧ões teóricas que possam embasar sua prática educacional, o que traz conseqüências funestas para a área (BARBOSA, 2002a).

Podemos destacar como principais conseqüências negativas da falta de embasamento teórico de professores de Arte na prática educacional: a falta de clareza em relação aos objetivos do ensino da Arte na escola (que benefícios traz ao educando) e, conseqüentemente, o desenvolvimento de atividades sem objetivos definidos (ALMEIDA, 2001).

A área, que foi considerada desde sempre como componente curricular de menor importância perante outras matérias de maior "peso" por alunos, professores das demais áreas e até pelos próprios Arte-Educadores, hoje, através de documentos federais (os quais serão abordados mais adiante no presente trabalho) é considerada como essencial na formação plena do indivíduo.

No entanto, observa-se através de pesquisas na área que tais constatações raramente extrapolam as linhas dos documentos para a realidade, tanto por razões históricas - amplamente abordadas por Barbosa (2002c) quanto por questões práticas, observáveis no dia-a-dia da sala de aula.

Os Parâmetros Curriculares Nacionais - documento federal que teve sua última versão publicada em 1998 - foram formulados com o intuito de regulamentar a prática educacional de professores de todas as áreas curriculares, do ensino fundamental ao médio. Através de suas sugestões ${ }^{2}$, formuladas a partir de bibliografia especializada e atualizada em cada área por teóricos conceituados pela comunidade científica em Educação, os educadores têm a oportunidade de fundamentar sua prática pedagógica, buscando uma melhor qualidade de ensino. O documento reconhece que há falta de fundamentação teórica por parte dos Arte-Educadores e, portanto, a

necessidade de estabelecimento de um quadro de referências conceituais solidamente fundamentado dentro do currículo escolar, focalizando a especificidade da área e definindo seus contornos com base nas características inerentes ao fenômeno artístico (BRASIL, 1998, p.22).

$\mathrm{O}$ documento se apresenta como uma opção para a solução do proble-

\footnotetext{
${ }^{1}$ Neste texto, o termo "arte" apresenta-se grafado com letra minúscula quando se refere à área do conhecimento humano, e com maiúscula quando essa área é componente curricular. ${ }^{2}$ Designamos como sugestões as constatações dos Parâmetros Curriculares Nacionais por sua aplicação não ser obrigatória no ensino.
} 
ma da ausência de referências conceituais de professores de todas as áreas. Porém, no caso específico do Ensino da Arte, objeto deste trabalho, tanto na rede pública de ensino, quanto na rede privada, as proposições apresentadas pelos PCN/Arte ${ }^{3}$ não se refletem na prática do ArteEducador: "... os PCN estão resultando muito pouco. (...) No Brasil, como vemos, nem a mera obrigatoriedade nem o reconhecimento da necessidade são suficientes para garantir a existência da Arte no currículo". (BARBOSA, p. 14, 2002a).

Focando o presente trabalho nos professores do Ensino Fundamental ( $5^{\mathrm{a}}$ a $8^{\mathrm{a}}$ Série) da Rede Pública Estadual de Ensino, sabemos que o referido material (PCN/Arte), teoricamente ${ }^{4}$, encontra-se disponível em todas as U.E. (Unidades de Ensino) da rede pública para eventuais consultas, além de ser amplamente utilizado em reuniões pedagógicas e capacitações de professores. A partir desse contexto, nos perguntamos por que, tendo disponível tal material teórico, professores não se pautam nos PCN/Arte para estabelecer seus objetivos educacionais, e por que não utilizam o documento para determinar suas convicções sobre em qual corrente ideológica se encontram inseridos. Conseqüentemente, nos indagamos: qual a importância do Ensino da Arte na Educação, de acordo com os referidos Parâmetros Curriculares?

Diante disso, percebemos a necessidade de refletirmos a respeito da(s) linha(s) teórica(s) de Arte-Educação adotada(s) no documento. Para tanto, procuraremos apresentar um panorama epistemológico do Ensino da Arte para que, a partir desta síntese de idéias, possamos ter parâmetros de diálogo entre as principais teorias que podem ser encontradas nos PCN.

Nessa reflexão, consideramos as concepções de ensino de Arte especificadas a seguir como pré-categorias de análise. Entendemos as categorias, como propõe Gomes (1994), como ferramentas para estabelecer classificações, ou seja: "agrupar elementos, idéias ou expressões em torno de um conceito capaz de abranger tudo isso" (p. 70). No caso de nossa investigação, os conceitos em questão seriam as concepções de ensino de Arte mais relevantes no meio educacional.

\section{MATERIALEMÉTODO}

Através de pesquisa bibliográfica e conseqüente diálogo promovido entre diversas propostas de classificações das concepções do ensino da Arte, determinamos algumas posições

\footnotetext{
${ }^{3}$ Estaremos, a partir daqui, assim nos referindo aos Parâmetros Curriculares Nacionais/ Arte, 1998 - Ensino Fundamental de $5^{\mathrm{a}}$ a $8^{\mathrm{a}}$ séries.

${ }^{4}$ Queremos dizer, com este termo, que esta é a informação oficial mas que, no entanto, não podemos garantir que ocorra na prática.
} 
filosóficas que sintetizam as idéias dos autores consultados, explicitando nosso posicionamento frente a essas idéias e colocando nossa própria proposta.

Cumpre ressaltar que, além de haver inúmeras propostas metodológicas no que concerne ao Ensino da Arte, a maneira como tais propostas podem ser classificadas entre si constitui, também, um outro nível de classificação. Assim, para podermos colocar tal confluência de idéias de forma organizada e apreensível ao leitor, optamos por iniciar o diálogo epistemológico pela classificação da classificação das concepções do ensino da Arte, a partir de Castanho (1982) e, a seguir, explicitaremos as concepções de Ensino de Arte propriamente ditas com base na divisão proposta por Eisner (2002a).

Tal divisão se constrói a partir de pesquisas do Ensino de Arte nos Estados Unidos. No entanto consideramo-la apropriada para analisarmos, também, o ensino de Arte no Brasil, pois teoricamente essas pesquisas foram fundamentadas em pressupostos construídos por autores renomados desse campo do saber e que são bastante citados em bibliografia da área no Brasil e no mundo: o próprio Elliot Eisner, Rudolf Arnhein, Viktor Lowenfeld, Sir Herbert Read, John Dewey, Ernest Gombrich, Pierre Francastel, Vincent Lanier, entre outros.

\section{DISCUSSÃO}

\section{CONTEXTUALISMO E ESSENCIALISMO}

A proposta de classificação das concepções de ensino de Arte em essencialista e contextualista é citada por vários pesquisadores da área de Arte-Educação. Com isso, a teoria de Elliot Eisner se coloca como uma das mais importantes a serem consideradas no presente trabalho.

Elliot Eisner, um dos precursores de $\mathrm{DBAE}^{5}$ (em Português, Arte-Educação como Disciplina), programa desenvolvido nos Estados Unidos pelo Getty Center for Education in the Arts (California, EUA), propõe tal classificação do ensino da Arte. Eisner formulou essa divisão a partir das posturas filosóficas postas no meio educacional dos Estados Unidos em relação ao ensino da Arte. $\mathrm{O}$ autor coloca a importância de se considerar a Arte como disciplina tão importante como as demais no currículo, com contornos próprios e conteúdos específicos a oferecer (EISNER, 2002b). Tal postura teórica se opõe à visão do ensino de Arte como mera experimentação de materiais, momento de relaxamento e/ou meio para se obter outros benefícios educacionais "extra-arte".

Na divisão proposta por Eisner, a corrente contextualista se propõe a

${ }^{5}$ Discipline-Based Art Education. 
utilizar a Arte como um meio para se atingir objetivos instrumentais não diretamente ligados à arte, mas sim às necessidades dos educandos (contexto psicológico) e da sociedade (contexto social). Já a corrente essencialista entende que a arte educa enquanto arte, trazendo benefícios ao educando próprios e exclusivos da área (EISNER, 1972).

Para Castanho (1982), à época de sua pesquisa, a proposta de Eisner não seria suficiente para englobar a diversidade existente de concepções educacionais de ensino de Arte, por não explicitar os critérios que levaram o autor a essa classificação. Coloca ser a divisão contextualismo-essencialismo "falsa", por não considerar o que realmente importa para o educador, que seria "a maneira como a arte pode contribuir, no que lhe é específico, para o desenvolvimento do comportamento humano, em seus aspectos intelectuais, emocionais, sociais, etc" (p.70). Entendemos que, para a autora, o mais relevante em uma possível classificação das concepções de ensino da Arte seria deixar claro, através dela, as contribuições que, dentro da perspectiva de tal ou tal opção, a Arte possa trazer ao educando em seu desenvolvimento enquanto indivíduo. Neste contexto,Castanho apresenta sua própria proposta de classificação das correntes teóricas em arte como intuição sensível e como "informante" do real.

A arte como intuição sensível seria a posição em que a arte é separada das outras formas de saber, de certa forma considerada inferior, por estar ligada "à magia, à inspiração, à sensibilidade, um campo em que a humanidade pode livrar-se da desumanização acarretada pelas outras atividades "sérias"" (CASTANHO, 1982, p. 71). Segundo a autora, tal concepção de ensino utiliza como práticas em sala de aula o desenvolvimento da auto-expressão do educando, a preocupação com o desenvolvimento das potencialidades e não a formação de artistas, a valorização do processo e não do produto artístico, e o desinteresse pelo desenvolvimento da apreciação artística. Tais práticas, no Brasil, sofrem forte influência da teoria de Viktor Lowenfeld, autor que caracterizou, do ponto de vista da psicologia, os estágios regulares no desenvolvimento da expressão artística do ser humano.

A arte como informante do real seria a posição que vê a arte como forma de conhecimento e, como tal, entende que ela deve ser incluída no âmbito educacional. Considera a existência de um pensamento plástico, que pode e deve ser desenvolvido como forma de explorar a realidade. Nessa concepção de ensino as convicções decorrentes seriam a valorização da apreciação artística, a idéia de que a arte se ensina (não é um “dom”), a valorização da pesquisa em Arte-Educação e a proposta de desenvolvimento de um pensamento visual (a partir da teoria de Pierre Francastel).

Almeida (2001), em seus estudos a respeito das concepções e práticas ar- 
tísticas presentes na escola, cita as concepções essencialista e contextualista de ensino. Afirma que a posição contextualista é a mais comumente assumida por professores da educação infantil e básica, quando eles consideram a Arte como um fator de desenvolvimento emocional e social dos alunos. Cita Vincent Lanier como defensor da concepção essencialista, pois tal autor reafirma os benefícios que o ensino da arte por si só traz à educação. A autora se coloca apenas parcialmente favorável à posição de Lanier, ao afirmar que simpatiza mais com as idéias dos autores contextualistas, pois, para estes, "o ensino das artes na escola não deveria se preocupar apenas com o desenvolvimento das habilidades, conhecimentos e valores exclusivos da área artística, mas também com a formação geral dos alunos" (ALMEIDA, 2001, p.13). Ao assumir uma postura diante da classificação de Eisner (2002a), entendemos que a autora não se opõe à mesma.

Ao discorrer sobre os caminhos metodológicos em Arte-Educação, Rizzi (2002, p. 65) também cita a classificação proposta por Eisner, ressaltando ser ele um dos autores de maior influência no debate conceitual do ensino da arte. A autora afirma que adeptos dessa categoria "sempre debateram e até mesmo brigaram a respeito da importância do ensino da Arte, seus objetivos e métodos de maneiras às vezes ainda sectária". Rizzi (2002) se insere na discussão da epistemologia que envolve o ensino da Arte, desta- cando que as escolhas conceituais dos educadores acabam por definir suas práticas metodológicas.

Compartilhamos a posição de Castanho (1982), ao entender que a divisão proposta por Eisner não é suficiente para englobar as opções conceituais existentes em Arte-Educação. Ao admitirmos que tais posturas determinam os objetivos metodo-lógicos empregados na prática escolar, observamos que muitas dessas práticas possuem características contextualistas e essencialistas.

Apesar de os demais autores citados não se colocarem contra a proposta de Eisner, observamos que nenhum deles utiliza as categorias propostas pelo referido teórico para classificar as práticas educacionais analisadas em suas investigações. Além disso, ao utilizarmos como base os três princípios de classificação para estabelecermos os conjuntos de categorias (GOMES, 1994, p. 72), estaríamos fugindo do princípio de que "as categorias do conjunto devem ser mutuamente exclusivas, ou seja, uma resposta não pode ser incluída em mais de uma categoria".

A partir de todas essas considerações, apresentaremos a nova proposta de classificação das concepções do ensino da Arte dada por Elliot Eisner $\mathrm{em}$ The Arts and the creation of mind (2002a). Cumpre ressaltar que não estaremos apresentando a classificação da classificação dessas concepções, mas dispondo-as de forma inteligível ao leitor sem organizá-las - ainda - em categorias mais gerais, como seria o 
caso de classificá-las em essencialistas ou contextualistas. No entanto, como já havíamos informado no presente texto, não consideramos tal opção satisfatória para categorizar as mencionadas concepções.

Não encontramos, em produções nacionais, citações de tal, obra provavelmente por se tratar de publicação bastante recente (2002) e, principalmente, por ainda não haver uma versão em Português. Tal proposta configurou-se a partir de pesquisas do autor feitas nos Estados Unidos; mas, com as devidas adaptações, acreditamos que possam se aplicar ao ensino de Arte no Brasil, já que as teorias do autor e as dos autores nos quais se embasa já são referência para diversas obras aplicadas à Arte-Educação de nosso país, conforme já havíamos ressaltado anteriormente no presente texto.

\section{NOVA PROPOSTA DE ELLIOT EISNER}

Eisner coloca, em The Arts and the creation of mind (2002a), que o mais importante em qualquer campo de atuação são as forças sociais que criam condições para que certos propósitos sejam adequados a certos momentos. Com isso entendemos que a importância dada a determinadas áreas do ensino se altera, do ponto de vista político-educacional, de acordo com convenções sociais e momentos históricos em que se encontram. Com isso fica claro o porquê da afirmação, colo- cada pelo autor, de que nem sempre os propósitos de uma área são definidos por seus pares. É dado como exemplo o ensino da matemática, que pode atender a diversos objetivos. Também opções diversas existem no ensino da Arte, pois os objetivos educacionais designados para a área podem variar de acordo com o contexto sócio-histórico em que forem analisados.

Com isso, Eisner (2002a) se propõe - além de se ater aos aspectos cognitivos do Ensino da Arte - a descrever separadamente algumas das visões de Arte-Educação de acordo com seus objetivos, sem o intuito (declarado) de estabelecer níveis de preferência entre elas.

A seguir apresentamos nossa interpretação das idéias expressas por Eisner, o que o autor chama de "Visions and versions of Arts Education", algo como Visões e versões da Arte-Educação. Paralelamente, estaremos colaborando com nossa visão pessoal e inserindo informações que permitam ao leitor relacionar as informações apresentadas com o Ensino de Arte no Brasil.

\subsection{DISCIPLINE-BASED ART EDUCATION}

Esta visão, que em português se aproxima de Arte-educação como disciplina, busca desenvolver nos alunos condições de adquirirem algumas competências consideradas necessárias para terem uma performance de alta qualidade em Arte. De acordo com 
esta concepção, para que tais competências sejam adquiridas, os alunos precisam desenvolver sofisticadas formas de pensar (2002a, p. 26). Essa perspectiva de Ensino tem como objetivos desenvolver a habilidade dos estudantes em criar e perceber a arte, e entender os contextos histórico e cultural em que as obras de arte se inserem e se infiltrarem nas questões filosóficas da estética.

No Brasil, podemos considerar a Proposta Triangular de Ana Mae Barbosa como uma precursora das idéias do DBAE, uma vez que propõe o ensino de Arte calcado na apreciação, fruição e contextualização da arte, interligadas entre si (2002b). Tal proposta, apresentada inicialmente pela autora através do livro $A$ imagem no Ensino da Arte, hoje se encontra bastante difundida no meio educacional. No entanto, nem sempre está presente na prática, configurando apenas uma "história documentada". Ou seja, acontece apenas nos documentos escritos (EZPELETA; ROCKWELL, 1986), não correspondendo ao cotidiano escolar "não documentado".

\subsection{VISUALCULTURE}

Tal concepção defende o uso da Arte como promotora do entendimento da "cultura visual". Ou seja, objeti- va fazer com que o aluno seja capaz de decodificar os valores e idéias mascarados no que se pode chamar de cultura popular tão bem quanto nas artes ditas "maiores".

De acordo com esta concepção de ensino, aprender a ler as mensagens presentes em um texto visual (imagem) é uma maneira de o indivíduo proteger seus direitos. A leitura de imagens pode proporcionar meios de ajudar a reverter situações de injustiça social, à medida que desvela os interesses que estão sendo privilegiados pelas imagens que nos cercam. Além disso, pode desenvolver a capacidade de usar a Arte como meio de entendimento dos valores e condições de vida daqueles que vivem em situações culturais diversas.

Tal perspectiva de ensino, permeada pelo contexto social da arte, permite o uso da mesma como meio para se compreender e desvelar códigos culturais diversos, promovendo dessa forma, a interpretação de significados como uma análise social e política.

Podemos fazer uma ponte entre tais idéias e as concepções multiculturais $^{6}$ de ensino, as quais são amplamente difundidas por Mason $^{7}$ (2001). A autora coloca-se como contextualista, ao afirmar que o Ensino da Arte deve contemplar di-

\footnotetext{
${ }^{6} \mathrm{O}$ multiculturalismo na escola pode ser entendido como “... a visão de que a variação cultural deve ser representada e transmitida no sistema escolar para que as crianças aceitemna em qualquer sociedade" (MASON, 2001).

${ }^{7}$ A autora revela que, atualmente, raramente utiliza o termo multiculturalismo por considerálo ambíguo (p. 13).
} 
versos códigos culturais em sua apresentação, promovendo o entendimento/aceitação da variação cultural através da Educação. Assim, através da diversificação cultural do currículo de Arte, pode-se detectar o eurocentrismo presente nas suas concepções bem como a parcialidade no estabelecimento do que são as Artes "maiores", pondo em questão os "princípios estéticos universais" (p. 12) pretensamente existentes.

Com isso, é posta abaixo a crença de que a "melhor" arte é aquela advinda da expressão pessoal (herança das artes de vanguarda), a "arte de ateliê", podendo-se incluir, ao conceito de arte, as artes populares, o folclore e as novas tecnologias.

Pode-se, com isso, observar uma clara oposição entre tais convicções e as propostas do DBAE, pois as habilidades tradicionais da arte, como o desenho e a pintura, perdem seu lugar privilegiado. Para Mason (2001, p, 13):

A arte-educação pós-moderna favorece as abordagens contextualistas, instrumentalistas, de fronteiras de cultura e interdisciplinar para o estudo da arte; ela traz questões internas assim como externas para a discussão da qualidade artística e não considera a forma como único conteúdo da arte.

Ainda que tais abordagens possuam também pontos de confluência, como a importância dada ao contexto histórico, político e social da arte na maneira como o objeto artístico deva ser "encarado", entendemos que as oposições conceituais entre elas destacam-se no que diz respeito às expectativas em relação à produção artística dos alunos. Enquanto, na proposta do DBAE, é exigida uma alta performance do aluno, na abordagem da Cultura Visual o processo crítico que envolve a produção artística é mais valorizado.

\section{3 PROBLEMSOLVING}

Nesta perspectiva de ensino, a arte é utilizada como ferramenta na "resolução criativa de problemas ${ }^{8 \%}$ no campo do design. O autor cita como principal exemplo desta concepção os pressupostos da escola Bauhaus, que ofereceu um programa de estudos na Alemanha,no período compreendido entre 1919 a 1930 . Os objetivos dos membros desta linha se pautavam no uso da máquina como modelo para se criar uma estética "limpa", explorando as características naturais dos materiais com os quais o designer trabalhava. A Bauhaus preparava e desenvolvia em seus alunos condições para que se tornassem "solucionadores criativos de problemas", sendo as qualidades estéticas dos produtos criados consideradas muito importantes.

$\mathrm{O}$ autor relata que tal perspectiva de ensino ainda possui seguidores

${ }^{8}$ Do inglês "creative problemsolving".

Olhar de professor, Ponta Grossa, 9(1):159-182, 2006. 
nos Estados Unidos. No Brasil, a influência da escola Bauhaus não é diretamente observada. No entanto, podemos destacar como tendo pontos em comum, com algumas ressalvas, as tendências educacionais do ensino de Arte difundidas por Rui Barbosa em meados de 1882/83,os quais revelam as influências do liberalismo e da revolução industrial na política nacional (BARBOSA, 2002c).

Para Rui Barbosa, o Desenho ${ }^{9}$ deveria ter destaque no currículo secundário e, especialmente, no primário. Com o intuito de enriquecer economicamente o país através do desenvolvimento industrial, considerava que isso só seria possível através da educação técnica e artesanal do povo (BARBOSA, 2002c, p. 44-45). Inspirado no modelo Americano de ensino da Arte, acreditava que a implantação do Desenho na educação secundária poderia render os mesmos frutos - a produção de bons desenhos de produtos industriais - obtidos nos Estados Unidos. As medidas instituídas por Rui Barbosa contribuíram para a proliferação de Liceus de Artes e Ofícios no Brasil, e as suas idéias sobre Educação Artística - pautadas em Walter Smith - passaram a ser defendidas como sustentáculo do progresso, educando o povo para o trabalho industrial (BARBOSA, 2002c, p. 53).
Cumpre ressaltar que a confluência de pressupostos entre a Bauhaus e as concepções de Desenho difundidas por Rui Barbosa no Brasil resume-se apenas na utilização do desenho para fins industriais. A proposta da Bauhaus valorizava a criatividade do aluno, possuindo cânones estéticos próprios, enquanto Smith dava ao desenho geométrico status de base para a realização de qualquer desenho, inclusive o artístico. Seu método de ensino consistia na apresentação, pelo professor, de modelos e esquemas para a realização de desenhos pelos alunos, sem que estes pudessem utilizar sua criatividade.

\subsection{CREATIVE SELF-EXPRESSION}

Esta quarta visão da Arte-Educação, articulada por Viktor Lowenfed e Sir Herbert Read, se propõe a desenvolver a arte através da auto-expressão criativa do aluno. Os autores em questão formularam suas teorias em contrapartida ao sistema educacional opressor existente no período da Segunda Guerra Mundial na Alemanha.

Ambos acreditam que maneiras de expressão não são “ensináveis”, e que qualquer tentativa de se oferecer técnicas ou padrões no ensino acaba produzindo inibições e frustrações à capacidade criadora. Tal perspectiva

9 O termo "desenho" apresenta-se grafado com letra minúscula quando se refere ao ato genérico de desenhar, e com maiúscula quando se refere a um componente curricular. 
se pauta na psicologia, sofrendo influências de Carl Jung e de Freud a partir das visões de Read e Lowenfeld, respectivamente. Os dois autores acreditam que os impulsos criativos encontram-se no inconsciente e que é dever do professor, especialmente do arte-educador, estimular seu afloramento sem, no entanto, interferir no seu processo natural. A função do professor, nesse caso, seria atender, guiar, inspirar, dar apoio psicológico ao educando.

Viktor Lowenfeld via a Arte como "meio para se compreender o desenvolvimento individual em suas diferentes fases e como desenvolvimento da consciência estética e criadora do indivíduo" (FUSARI e FERRAZ, 2001, p. 38). Desenvolveu, através de suas pesquisas, oito critérios para a classificação da criatividade.

No Brasil, a auto-expressão no ensino da Arte ainda possui muitos adeptos, sendo a mais enfatizada na educação escolar brasileira até a década de 90. Popularizou-se através do movimento conhecido por Escolanovismo ou Escola Nova, principalmente a partir de 1930 (FUSARI, FERRAZ, 2001).

John Dewey, um dos idealizadores da Escola Nova, representou, juntamente com Lowenfeld e Read, influência marcante na transformação da prática do Ensino de Arte no Brasil. Dewey alertava para a função educativa da experiência, enfatizando sua importância no processo de aprendizagem (FUSARI; FERRAZ, 2001, p. 36).

Castanho (1982), ao discorrer a respeito da influência da obra de Lowenfeld no Brasil, atenta para o fato de que o campo da arte-educação, por ser de discussão científica ainda incipiente $^{10}$, pode sofrer mais facilmente influências de construções teóricas bem acabadas e, com isso, ganhar adeptos desavisados (CASTANHO, 1982, p. 82).

Apesar das visões de Bauhaus, e Lowenfeld, e de Read e Dewey se pautarem na criatividade, apresentam abordagens totalmente distintas. Enquanto a primeira se foca na solução de problemas práticos utilizando materiais diversos, a segunda encoraja crianças a esculpir e pintar, buscando extrair expressões criativas de suas experiências pessoais, incluindo suas fantasias infantis. A influência do professor é mínima, com pouca ou nenhuma atenção ao contexto histórico da arte. No entanto, uma idéia dominante nas duas abordagens é considerar que a criança e sua arte se desenvolvem muito mais de dentro para fora do que de fora para dentro (EISNER, 2002a, p.33).

A crença, ainda muito difundida no Brasil, na "virgindade expressiva" da criança, é altamente combatida por alguns autores, em especial por Ana

10 À época de sua pesquisa - 1982 - tais discussões eram ainda mais escassas do que atualmente, e a Arte ainda não era considerada área do saber e sim "atividade escolar". 
Mae Barbosa. A autora afirma ser a contextualização da obra de Arte extremamente importante, principalmente por combater a idéia de os cânones artísticos serem neutros. Afirma ainda que a criança, mesmo não escolarizada, possui juízos de valor formados a partir de sua criação familiar, pelos meios de comunicação a que tem acesso e pela cultura local. Sendo assim, a orientação estética do professor de Arte não estaria, de forma alguma, violando seu pretenso potencial criador puro de influências, pois este não existe.

\subsection{ART EDUCATION AS PREPARATIONFORTHE WORLD OF WORK}

A quinta visão da Arte-Educação proposta por Eisner usa a Arte para desenvolver as habilidades e atitudes necessárias ao ambiente de trabalho.

Muito se fala sobre a melhora da escola para que isso fortaleça a competitividade econômica de um país frente à economia mundial. Nos Estados Unidos tal concepção é muito forte, atingindo até mesmo o ensino da Arte.

Os que assumem acreditam que a experiência em Arte desenvolve a iniciativa e a criatividade, estimula a imaginação, desenvolve a capacidade criadora e, em alguns campos da arte, ajuda os jovens a aprenderem a trabalhar em grupo.

Para muitos, a justificativa de se utilizar a Arte como forma de prepara- ção para o trabalho é a mais persuasiva existente, com o argumento de que a experiência estética pode ser de alguma valia, porém há meios de ser assegurada fora da escola. Já a preparação para o trabalho é algo que será um dia necessário a todo estudante.

\subsection{THE ARTS AND COGNITIVE DEVELOPMENT}

Esta visão enfatiza as conseqüências cognitivas do trabalho com Arte, ao acreditar que contribui no desenvolvimento de complexas e sutis formas de pensamento. Ironicamente, segundo Eisner (2002a), nem sempre a Arte esteve ligada à cognição.

Num tempo em que o desenvolvimento das habilidades mentais é particularmente importante e, segundo o autor, em que as escolas devem preparar pessoas para trabalharem com mais de uma ocupação durante a vida, a presença de um programa que adote a flexibilidade, promova a tolerância pela ambigüidade e dependa do exercício do julgamento, numa esfera de regras escolares pode ser um valoroso recurso.

Eisner coloca que o modo como experienciamos o mundo é influenciado pela cultura, pela linguagem e pelas crenças e, ao mesmo tempo, moderado pela nossa individualidade, nossa própria maneira de apreender a realidade. $\mathrm{O}$ autor explica que, através da representação podemos tornar concretas as imagens ou idéi- 
as que produzimos através das nossas experiências. A representação, para Eisner, é um evento cognitivo que se dá através da gravação (inscription), da edição (editing), da comunicação (comunication) e da surpresa (surprise). A inscrição seria o modo de se preservar a idéia ou imagem tida (nunca da exata forma em que foi originalmente experienciada) em algo durável e concreto. Através da edição prestamos atenção às relações, aos detalhes; ela é, pois, um aspecto crucial do processo criativo, um meio de eliminarmos as falhas. A comunicação, terceira função cognitiva da representação, transforma a consciência em uma forma pública. A surpresa, que, segundo o autor, seria a principal recompensa de todo trabalho criativo, torna possível que uma seja possível pessoa se surpreenda com algo feito por si mesma, e que não saiba como repeti-lo da mesma forma (EISNER, 2002a, p. 6-8).

Para Eisner (2002a), a comunicação propicia trocas de contribuições entre indivíduos, configurando uma relação simbiótica. É através dessas relações que nos desenvolvemos, trocamos experiências com o outro. Assim, a educação deve propiciar tais relações simbióticas para que possamos desenvolver habilidades distintas e complementares às nossas. Podemos citar como representantes des- ta concepção Rudolph Arnhein e Ulric Neisser, que também viam a percepção como um evento cognitivo.

$\mathrm{O}$ autor enfatiza que qualquer trabalho de qualidade em arte requereria sutis e sofisticadas formas de pensamento, mas há abordagens mais apropriadas para promover o desenvolvimento cognitivo. Exemplifica com programas que fazem o estudante contextualizar seus próprios propósitos nas formas artísticas com as quais vai trabalhar, programas que fazem o aluno refletir a respeito de seu próprio processo de criação e aqueles que encorajam o aluno a articular suas produções com seus julgamentos sobre arte.

A chave desta abordagem é desenhar o currículo com base nas formas de cognição e entendimento que se pretende desenvolver.

\subsection{USING THE ARTS TO PROMOTE ACADEMIC PERFORMANCE}

Esta sétima versão está relacionada à justificação do Ensino da Arte pela sua (possível) contribuição no auxílio a outras matérias ditas bási$\operatorname{cas}^{11}$. Como já havia sido mencionado, a receptividade da sociedade pelos objetivos de um campo de estudo está altamente relacionada com o que realmente se consegue executar des-

\footnotetext{
${ }^{11}$ Aqui o autor se refere às disciplinas de Ciências e Matemática, o que, no Brasil, poderia ser transposto para Português e Matemática.
} 
ses objetivos. Este é certamente o caso de se tentar usar a arte para auxiliar na performance acadêmica dos estudantes. Isso envolve a premissa de que quanto mais cursos de arte crianças e jovens tiverem, melhores serão suas performances na escola. $\mathrm{Na}$ área de música temos o que é chamado "Mozart Effect". (RAUSCHER; SHAW apud EISNER, 2002a). Bebês e crianças em idade pré-escolar expostas à música clássica várias vezes na semana se saem melhor em testes de habilidade espacial do que outras crianças não expostas. Alguns acreditam que esse resultado possa significar que a música torna as pessoas mais "espertas"12.

Outro dado, proveniente de uma pesquisa em maior escala, mostra que estudantes matriculados em cursos de arte no segundo grau ${ }^{13}$ conseguem notas significativamente maiores no SAT (Scholastic Achievement Test ${ }^{14}$ ) do que os que não os fazem: quanto mais cursos de arte, maior a nota no SAT. No entanto, mais cursos em qualquer campo do saber podem ser associados com um alto desempenho em avaliações. Na verdade, disciplinas relacionadas às áreas de Ciências e Matemática são consideradas mais diretamente relacionadas com o bom desempenho no referido teste. Pondo de lado a adequação da pesquisa descrita, o objetivo proposto por esta visão é usar a arte como um meio para aprimorar o que alguns consideram mais importante: notas maiores em Matemática e Ciências.

Para Eisner (2002a), as razões para tal objetivo parecem por demais claras. Tantos esforços têm sido feitos para melhorar a performance acadêmica dos estudantes, que se está perdendo a razão em busca disso. Depois de diversas tentativas frustradas durante os anos oitenta ${ }^{15}$, tem-se a sensação de que nenhum desses esforços surtiu efeito. A partir dessas circunstâncias, as pessoas se perguntam: "Por que não tentar a arte?".

Eisner (2002a) afirma que, para alguns arte-educadores, principalmente os que se sentem profissionalmente marginalizados, essa nova utilidade da arte serve como um bote salva-vidas. $\mathrm{O}$ autor coloca algumas questões à luz das seguintes considerações:

- Pode um campo do saber fazer sua contribuição mais importante através da busca de resultados que outros campos deveriam atingir por si sós?

\footnotetext{
${ }^{12}$ Do inglês smarter.

${ }^{13}$ Nos EUA, os estudantes que cursam o equivalente ao segundo grau no Brasil podem optar por algumas das matérias que desejam cursar.

${ }^{14}$ Teste similar ao ENEM (Exame Nacional do Ensino Médio) do Brasil, pois são realizados por estudantes em idade escolar próxima.

${ }^{15}$ São aqui descritas pelo autor diversas políticas norte-americanas de tentativas de aprimoramento dos índices de performance escolar.
} 
- Seria possível obter dados que comprovem os efeitos da arte na performance de outras disciplinas?

- O que acontece com as razões para a existência de um campo do saber na escola, se uma pesquisa mostra que seus objetivos estão desatualizados, ou que seus pressupostos são fracos, ou que outra proposta de aprimoramento da performance escolar seja considerada mais eficiente?

Diante de tais questionamentos, é clara a postura crítica de Eisner quanto à referida visão de ensino.

\subsection{INTEGRATEDARTS}

Outra visão da Arte-Educação concebe o currículo em Arte como integrante do currículo de outras artes e outras áreas. Esta concepção, denominada por Eisner (2002a) de "integrated arts" (artes integradas), é comumente usada como forma de aprimoramento da experiência educacional do estudante. O Currículo de "Artes Integradas" é tipicamente organizado a partir de uma possibilidade curricular dentre quatro estruturas possíveis.

Primeiramente, a arte é utilizada como ferramenta no entendimento de um momento histórico particular ou cultura. Por exemplo, o estudo de uma guerra civil poderia incluir as fotografias da época (se houver) ou a música e arquitetura do período. Poderiam ser exploradas as formas de vestimenta de pessoas pertencentes a diferentes classes sociais, assim como poder-seia resgatar a literatura da época. $\mathrm{O}$ objetivo é aprofundar a amplitude do entendimento do aluno através da utilização de materiais relacionados ao período histórico estudado que, ao final, podem falar mais do que meros textos escritos. Portanto arte, música, literatura e história unem-se ao redor de um período histórico particular.

Uma segunda forma de integração, esta no âmbito da própria arte, pretende auxiliar os alunos a identificarem as similaridades e as diferenças entre as diversas formas de arte. Por exemplo, todas as artes estão relacionadas à criação de formas expressivas, mas os meios utilizados para atingir tal objetivo não são os mesmos em cada uma delas. A partir desta proposta, os estudantes têm a oportunidade de descobrir o que as artes têm em comum e também o que as distingue entre si.

Uma terceira abordagem é identificar um tema ou idéia gerador(a) que possa ser explorado(a) através do trabalho não somente com arte, mas também com outras áreas do saber. O conceito de metamorfose, por exemplo, pode ser ilustrado pelo modo como uma melodia é alterada em uma sinfonia ou pela mudança em uma seqüência de imagens em um filme.

Uma quarta estrutura para a integração das artes está relacionada à prática de solução de problemas. Os alunos podem ser convidados a definir um problema que requisite a participação de diversas disciplinas, in- 
cluindo a arte. Por exemplo, a montagem de uma peça teatral na qual precisem determinar a construção e desenvolvimento dos objetivos, aspectos físicos dos materiais, roteiro, aspectos estéticos que serão considerados, etc. Em outras palavras, o problema em si terá múltiplas perspectivas que precisarão ser integradas num todo para que a peça possa acontecer com sucesso.

Tal perspectiva, no Brasil, possui similaridades com as propostas de ensino por projetos e interdisciplinaridade, como procuraremos demonstrar a seguir. Antes, é importante lembrar que termos pluridisciplinaridade, interdisciplinaridade e transdisciplinaridade são hoje encontrados com significados próprios. Segundo Pereira e Hannas:

- a pluridisciplinaridade ou multidisciplinaridade refere-se às disciplinas específicas;

- a interdisciplinaridade refere-se à correlação entre os conteúdos das disciplinas;

- a transdisciplinaridade transcende as disciplinas, levando em conta não somente sua abordagem, mas sobretudo, propondo uma abertura de todas para o que ocorre nelas e além delas. A abordagem transdisciplinar é aberta para o que vai além do campo das ciências exatas, reconciliando-as com as humanidades, ciências sociais, literatura, arte, poesia, experiência interior (PEREIRA; HANNAS, 2000, p. 180).

Cumpre ressaltar que nosso intuito não é o de nos posicionarmos fren- te a tais conceitos; todavia, fica clara a posição das autoras ao se estenderem na definição do conceito de transdisciplinaridade. Podemos notar as similaridades entre tais propostas e a visão da Arte integrada de Eisner (2002a), pois ele propõe, grosso modo, trocas e complementações entre as áreas do saber, de forma a enriquecer a aprendizagem do aluno. É interessante também observar que as autoras se "pré-defendem" da acusação de estarem colaborando com um modismo, ao citarem uma frase de Ubiratan D’Ambrósio que diz, da transdisciplinaridade: "Nem é, como alguns insistem em mostrá-la, um modismo" (apud PEREIRA; HANNAS, 2000, p. 181).

A pedagogia de projetos é definida não somente como a "escolha de um tema para trabalhar em todas as áreas", mas reflete "uma visão da educação escolar, na qual a experiência vivida e a cultura sistematizada interagem, na medida em que os alunos vão estabelecendo relações entre os conhecimentos construídos em sua experiência escolar e na vida extra-escolar" (Brasil, 1998, p.61). Tal definição, encontrada nos Cadernos da TV Escola, material disponibilizado na Internet pela Secretaria do Estado da Educação de São Paulo, reflete as tendências de ensino defendidas hoje pelo estado. Podemos perceber com clareza a proximidade entre tais tendências e a Prática de Soluções de Problemas observada por Eisner (2002a), na qual alunos e profes- 
sor(es) mobilizam-se sobre um tema e, através dele, podem desenvolver atividades que abracem diversas áreas do saber, promovendo um ambiente de aprendizagem que contemple uma pluralidade de dimensões.

\section{RESULTADOS}

Através da apresentação e conseqüente diálogo entre as propostas de concepções vigentes do ensino de Arte, procuramos levantar pré-categorias de análise que pudessem ser utilizadas na classificação das concepções de ensino de Arte presentes nos PCN/Arte. Elegemos a classificação do teórico Elliot Eisner (2002a) como parâmetro para nosso estudo, por se tratar de um teórico amplamente citado em bibliografia da área.

Assim, elegemos como possíveis pré-categorias:

I. Arte-Educação como Disciplina

II. Arte como Cultura Visual

III. Arte para o Desenho técnico

IV. Arte como Auto-Expressão Criativa

V. Arte para o mercado de trabalho

VI. Desenvolvimento cognitivo através da Arte

VII. Arte como promotora da Performance Acadêmica

VIII. Arte integrada

Tal classificação pode ser utilizada como instrumento conceitual facilitador na compreensão dos pressupostos teóricos que se encontram inseridos nos Parâmetros Curriculares Nacionais de Arte, ainda que de forma não declarada. Com isso, a aceitação/adoção dos PCN por parte do professorado a que se destina pode acontecer de forma mais consciente e crítica, atendendo à objetivos educacionais específicos com os quais o educador deseja se comprometer.

Assim, estaremos apresentando de forma sintética a análise dos Parâmetros Curriculares Nacionais/ Arte para os $3^{\circ}$ e $4^{\circ} \mathrm{Ciclos}$ do Ensino Fundamental com base nas categorias eleitas em nosso estudo, bem como evidenciando as confluências e oposições conceituais a que fazemos referência no título do presente texto.

\section{ASCONCEPÇÕESTEÓRICASDO ENSINO DAARTE E SEUS REFLE- XOS NOS PCN/ARTE}

\subsection{ARTE-EDUCAÇÃO COMO DIS- CIPLINA}

Como já havíamos especificado no presente texto, a linha conceitual da Arte-Educação como Disciplina tornou-se conhecida no Brasil através da Proposta Triangular de Ana Mae Barbosa (advinda das idéias da Discipline Based Art-Education), a qual propõe o ensino da arte calcado no fazer artístico, na história da arte e na análise de obras de arte (BARBOSA, 2002b).

A proposta metodológica dos PCN/Arte fundamenta-se basicamente na Proposta Triangular, estabele- 
cendo três eixos de aprendizagem norteadores: "produzir, apreciar e contextualizar" (BRASIL, 1998, p. 49). É claramente observável a correspondência entre as seguintes propostas: fazer artístico/produzir, história da arte/contextualizar e análise de obras de arte/apreciar.

A adesão dos PCN aos pressupostos teóricos da Proposta Triangular já se manifesta na Introdução do documento, ao assumir que o desenvolvimento da cultura de arte do aluno se dá "[...] fazendo, conhecendo e apreciando produções artísticas" (BRASIL, 1998, p.19), e se confirma, principalmente, no subtítulo "Caracterização geral e eixos de aprendizagem" (p. 49), onde os chamados "eixos de aprendizagem" são definidos um a um:

Produzir refere-se ao fazer artístico (como expressão, construção, representação) e ao conjunto de informações a ele relacionadas, no âmbito do fazer do aluno e do desenvolvimento de seu percurso de criação. $\mathrm{O}$ ato de produzir realiza-se por meio da experimentação e uso das linguagens artísticas.

Apreciar refere-se ao âmbito da recepção, incluindo percepção, decodificação, interpretação, fruição de arte e do universo a ela relacionado. A ação de aprender abrange a produção artística do aluno e a de seus colegas, a produção histórico-social em sua diversidade, a identificação de qualidades estéticas e significados artísticos no cotidiano, nas mídias, na indústria cultural, nas práticas popu- lares, no meio ambiente.

Contextualizar é situar o conhecimento do próprio trabalho artístico, dos colegas e da arte como produto social e histórico, o que desvela a existência de múltiplas culturas e subjetividades" (Grifo nosso, BRASIL, 1998, p. 50).

Portanto, as propostas dos Parâmetros Curriculares Nacionais de Arte para $5^{\mathrm{a}}$ a $8^{\mathrm{a}}$ séries estão submetidas à orientação geral apresentada na primeira parte do documento "Arte no ensino fundamental" (p. 19-54), cujas diretrizes fundamentam-se nos eixos de aprendizagem da Proposta Triangular e devem ser estendidas às diversas linguagens artísticas: artes visuais, música, teatro e dança. Contudo, são observadas também influências de outras concepções teóricas do ensino da arte em alguns trechos do documento.

\subsection{ARTECOMOCULTURAVISUAL}

A perspectiva conceitual da Arte como Cultura Visual manifesta-se amplamente nas propostas dos $\mathrm{PCN}$, diluída na maioria dos tópicos abordados.

A questão da importância de se enfatizar as diferenças culturais das múltiplas sociedades humanas por meio do ensino da arte é sugerida em diversos momentos, além do comprometimento que a arte deve ter em auxiliar o aluno a interpretar a diversidade de valores presente na sociedade, combatendo preconceitos e a exclusão social, ou seja, contribuindo para 
que o aluno possa defender seus direitos e proporcionando meios de ajudar na reversão de situação de injustiça social.

Podemos exemplificar isso com os seguintes trechos dos PCN:

Produzindo trabalhos artísticos e conhecendo essa produção nas outras culturas, o aluno poderá compreender a diversidade de valores que orientam tanto seus modos de pensar e agir como os da sociedade (Grifo nosso, p. 19).

Além disso, os alunos tornam-se capazes de perceber sua realidade cotidiana mais vivamente, reconhecendo e decodificando formas, sons, gestos, movimentos que estão à sua volta (Grifo nosso, p.19).

A área de Arte contribui, portanto, para ampliar o entendimento e a atuação dos alunos ante os problemas vitais que estão presentes na sociedade de nossos dias (Grifo nosso, BRASIL, 1998, p. 38).

Identificar, relacionar e compreender a arte como fato histórico contextualizado nas diversas culturas conhecendo, respeitando e podendo observar as produções presentes no entorno, assim como as demais do patrimônio cultural e do universo natural, identificando a existência de diferenças nos padrões artísticos e estéticos de diferentes grupos culturais (Grifo nosso, p. 48).

1.4ARTE PARA O DESENHO TÉCNICO

Não encontramos influências des- ta corrente teórica nos PCN/Arte. Apesar de haver muitas menções no documento a respeito da criatividade no processo de criação artística, o próprio documento critica a justificação da arte no currículo apenas com o intuito de desenvolvê-la (a criatividade):

[...] muitos dos objetivos arrolados nos planejamento dos professores de arte poderiam compor outras disciplinas do currículo, como desenvolver a criatividade, a sensibilidade, o autocontrole, etc (BRASIL, 1998, p. 22).

\subsection{ARTE COMO AUTO-EXPRES- SÃOCRIATIVA}

A ênfase na emoção, na intuição, na sensibilidade, na personalidade do artista denota influências das correntes teóricas que enfatizam a livre-expressão. Com isso há uma certa mistificação da obra de arte que, segundo Penna e Alves (2001),

[...] em nada contribui para a compreensão da arte ou de seu ensino, pois os fatores que, segundo esta concepção, determinam a atividade artística, independem totalmente de uma ação pedagógica.

Em seus estudos sobre a fundamentação teórica dos PCN de Arte do Ciclo I ( $1^{\mathrm{a}}$ a $4^{\mathrm{a}}$ séries $)$, Penna e Alves concluíram haver uma grande influência da concepção romântica de arte:

Nos PCN-Arte para as séries iniciais, a forte influência da concepção romântica de arte é bastante evidente: há uma 
supervalorização da emoção, com ênfase na sensibilidade inventiva (...) (2001).

Os autores destacam ainda a influência do romantismo nas correntes da arte-educação que enfatizam a livre expressão, "repudiando qualquer interferência no desenho da criança e defendendo uma visão romântica da infầncia”(PENNA e ALVES, 2001).

Há vários trechos nos PCN/Arte de $5^{\mathrm{a}}$ a $8^{\mathrm{a}}$ séries onde podemos encontrar traços da influência da livre-expressão criativa, com ênfase na personalidade do artista e na sua emoção:

O motor que organiza esse conjunto é a sensibilidade, a intuição, a imaginação, os conhecimentos, a emoção, que desencadeiam o dinamismo criador do artista (Grifo nosso, BRASIL, 1998, p. 34).

Diante de uma obra de arte, intuição, raciocínio e imaginação atuam tanto no artista como no espectador (p. 33).

Assim, a fundamentação dos PCN/Arte possui marcas da tendência da livre-expressão criativa, cujas bases teóricas são incompatíveis com os pressupostos expostos na primeira categoria.

\subsection{ARTE PARA O MERCADO DE TRABALHO}

Há apenas uma menção à possível contribuição da arte para o mercado de trabalho nos PCN/Arte para o Ciclo II:

A ação artística também costuma envolver criação grupal: nesse momento a arte contribui para o fortalecimento do conceito de grupo. $\mathrm{O}$ aluno pode compreender o outro intelectual e afetiva-mente e pode ter atitudes cooperativas nos grupos de trabalho (BRASIL, 1998, p. 61).

Não consideramos essa influência marcante nas concepções teóricas dos PCN/Arte, pois a mencionada menção a "grupos de trabalho" pode ser interpretada como grupos de trabalho escolares.

\subsection{DESENVOLVIMENTO COG- NITIVOATRAVÉS DAARTE}

Enfatizando as conseqüências cognitivas do trabalho com Arte e acreditando que a arte contribua no desenvolvimento de complexas e sutis formas de pensamento, esta categoria assume a representação como um evento cognitivo.

Para Eisner, a representação se dá através de processos denominados gravação, edição, comunicação e surpresa. Essa forma de ver a arte não apenas como área de conhecimento, mas como promotora de eventos cognitivos unicamente provenientes da representação artística não está presente nos PCN/Arte.

\subsection{ARTE COMO PROMOTORA DAPERFORMANCEACADÊMICA}

Esta perspectiva do ensino da arte tem como ponto chave justificar a presença da arte no currículo pela possível contribuição as outras disciplinas consideradas "básicas". 
A proposta dos PCN considera a Arte como disciplina com conteúdos próprios e importância em si:

[...] a atual legislação brasileira reconhece a importância da arte na formação e desenvolvimento de crianças e jovens, incluindo-a como componente curricular obrigatório da educação básica. No ensino fundamental a Arte passa a vigorar como área de conhecimento e trabalho coma as várias linguagens e visa à formação artística e estética dos alunos (BRASIL, 1998, p. 19).

No entanto, a possível contribuição é destacada:

[...] ao fazer e conhecer arte, o aluno percorre trajetos de aprendizagem que propiciam conhecimentos específicos sobre sua relação com o mundo. Além disso, desenvolvem potencialidades (como percepção, observação, imaginação e sensibilidade) que podem contribuir para a consciência do seu lugar no mundo e para a compreensão de conteúdos de outras áreas do currículo (Grifo nosso, p. 43).

Assim, apesar de não considerarmos marcante esta influência teórica nos PCN/Arte, salientamos mais uma vez a presença de noções com bases teóricas incompatíveis no documento.

\subsection{ARTE INTEGRADA}

Nesta perspectiva de ensino, alunos e professor(es) mobilizam-se sobre um tema para que possam desenvolver atividades que abracem diversas áreas do saber e promovam um ambiente de aprendizagem que con- temple uma pluralidade de dimensões.

A proposta dos PCN/Arte para o tratamento dos temas transversais através da arte considera a área como "campo privilegiado" para essa incumbência, contribuindo para a contextualização dos referidos temas.

No tópico "Arte e questões sociais da atualidade: os temas transversais" (BRASIL, 1998, p. 37), são sugeridas formas de os temas transversais serem trabalhados através da arte e em conjunto com as outras áreas do conhecimento. Os temas propostos são:

ética, meio ambiente, orientação sexual, saúde, trabalho, consumo e cidadania, comunicação e tecnologia informacional, pluralidade cultural, além de outros temas locais definidos na organização escolar" (BRASIL, 1998, p. 38).

A correspondência entre a proposta para os temas transversais e a categoria Arte integrada é clara ao considerar a arte como condutora de um projeto de trabalho no qual são contempladas várias áreas do currículo em torno de um tema comum.

\section{CONFLUÊNCIAS CONCEITUAIS}

As categorias eleitas possuem suas especificidades, mas têm também pontos em comum. Podemos tomar como exemplo as categorias Arte-Educação como Disciplina e Arte como Cultura Visual, pois ambas contemplam a importância de se considerarem os contextos social e histórico da 
arte no ensino. No caso da categoria Arte-Educação como Disciplina percebe-se a importância dada à valorização da contextualização das produções artísticas. Já na categoria Arte como Cultura Visual observa-se a importância dada às diferenças de códigos culturais presentes nas produções, diferenças essas ocasionadas pelas variações sociais e históricas existentes entre as diversas sociedades que produzem arte.

\section{OPOSIÇÕES CONCEITUAIS}

Os PCN/Arte possuem suas bases teóricas fundamentadas na Proposta Triangular. No entanto, apresentam também influências de outras linhas teóricas, por vezes incompatíveis.

Consideramos como principal oposição conceitual presente nos $\mathrm{PCN} /$ Arte a que existe entre a visão da arte como livre expressão criativa, expressa em trechos nos quais se enfatiza a emoção, a intuição e a personalidade do artista, e a da arte como conhecimento, defendida pela Proposta Triangular.

\section{CONSIDERAÇÕES FINAIS}

Apesar de apresentarem uma proposta muito abrangente e buscarem resgatar os conhecimentos específicos da arte, os PCN/Arte de $5^{\mathrm{a}}$ a $8^{\mathrm{a}}$ séries, ao longo do texto de funda- mentação, apresentam trechos onde se entrecruzam noções com bases teóricas diferenciadas ou mesmo incompatíveis.

A opção teórica dos PCN/Arte foi a de embasar os eixos norteadores na Proposta Triangular, havendo, no entanto, trechos onde são observadas influências de teorias distintas e mesmo opostas, o que compromete seu entendimento e realização.

Não estamos aqui desconsiderando a importância dos PCN/Arte, pois colaboram na legitimação da presença da arte na escola e são uma tentativa de redirecionamento do seu ensino, ao qual trazem grandes contribuições.

Entretanto, concluímos haver a necessidade de rever as noções teóricas utilizadas no documento, para que a sua finalidade - oferecer fundamentos teóricos para embasarem a prática pedagógica dos professores de arte - possa ser mais facilmente atingida.

\section{REFERÊNCIAS}

ALMEIDA, C. M. de C. Os modelos tradicionais de Ensino em Arte e a emergência de novas metodologias. Núcleo de publicações CED, Florianópolis, n. 01. UFSC, 2001.

Concepções e práticas artísticas na escola. In: FERREIRA, S. (Org.). $O$ ensino das artes: construindo caminhos. São Paulo: Papirus, 2001. p. 11-38.

ALMEIDA, J. F. de; PINTO, J. M. Da teoria à investigação empírica: problemas 
metodológicos gerais. In: SILVA, A. S. e PINTO, J. M. (Orgs.). Metodologia das ciências sociais. Porto (Portugal): Edições Afrontamentos, 2001.

-----BARBOSA, A. M. As mutações do conceito e da prática. In:

(Org.). Inquietações e mudanças no ensino da arte. São Paulo: Cortez, 2002a. p. 13-26.

A imagem no ensino da arte: anos oitenta e novos tempos. São Paulo: Perspectiva, 2002b.

Arte-Educação no Brasil. São Paulo: Perspectiva, 2002c.

BRASIL. Secretaria de Educação Fundamental. Parâmetros Curriculares Nacionais: arte. Ensino de quinta a oitava séries. Brasília: MEC/SEF, 1998.

BRASIL. Secretaria da Educação a Distância/MEC. Cadernos da TV Escola: Diários - Projetos de Trabalho. Brasília: MEC/SEF, 1998 b.

CASTANHO, M. E. Arte-educação e intelectualidade da arte. 1982. Dissertação (Mestrado em Educação) - Universidade Estadual de Campinas, Campinas, 1982.

EISNER, E. W. The arts and the creation of mind. London: Yale University Press/New Haven \& London, 2002a.

. Estrutura e mágica no ensino da arte. In: BARBOSA, A. M. (Org.). Arte-educação: leitura no subsolo. São Paulo: Cortez, 2002b. p.79-96.

Educating artistic vision. New York: The Macmillan Company, 1972.

EZPELETA, J.; ROCKWELL, E. Pesquisa participante. São Paulo: Cortez \&
Autores Associados, 1986.

FUSARI, M. F. de R.; FERRAZ, M. H. C. de T. Arte na educação escolar. São Paulo: Cortez, 2001.

GOMES, R. A análise de dados em pesquisa qualitativa. In: MINAYO, M. C. de S. (Org.). Pesquisa social: teoria, método e criatividade. Petrópolis: Vozes, 1994.

MASON, R. Por uma arte-educação multicultural. Campinas: Mercado das Letras, 2001.

PEREIRA, I. L. L. e HANNAS, M. L. Educação com consciência: fundamentos para uma nova abordagem pedagógica. São Paulo: Editora Gente, 2000.

RIZZI, M. C. de S. Caminhos Metodológicos. In: BARBOSA, A. M. (Org.). Inquietações e mudanças no ensino da arte. São Paulo: Cortez, 2002. p. 63-70.

Encaminhado em: 03/10/05

Aceito em: 24/02/06 